\title{
Stress-related hormone norepinephrine induces interleukin- 6 expression in GES-1 cells
}

\author{
R. Yang, Q. Lin, H.B. Gao and P. Zhang
}

Department of Biochemistry and Molecular Cell Biology, School of Medicine, Shanghai Jiao Tong University, Shanghai, China

\begin{abstract}
In the current literature, there is evidence that psychological factors can affect the incidence and progression of some cancers. Interleukin 6 (IL-6) is known to be elevated in individuals experiencing chronic stress and is also involved in oncogenesis and cancer progression. However, the precise mechanism of IL-6 induction by the stress-related hormone norepinephrine (NE) is not clear, and, furthermore, there are no reports about the effect of NE on IL-6 expression in gastric epithelial cells. In this study, we examined the effect of NE on IL-6 expression in immortalized human gastric epithelial cells (GES-1 cells). Using realtime PCR and enzyme-linked immunoassay, we demonstrated that NE can induce IL-6 mRNA and protein expression in GES1 cells. The induction is through the $\beta$-adrenergic receptor-cAMP-protein kinase A pathway and mainly at the transcriptional level. Progressive 5'-deletions and site-directed mutagenesis of the parental construct show that, although activating-protein-1 (AP-1), cAMP-responsive element binding protein (CREB), CCAAT-enhancer binding protein- $\beta$ (C/EBP- $\beta)$, and nuclear factor $\kappa$-light-chain-enhancer of activated $B$ cells $(N F-\kappa B)$ binding sites are all required in the basal transcription of IL-6, only AP-1 and CREB binding sites in the IL-6 promoter are required in NE-induced IL-6 expression. The results suggest that chronic stress may increase IL-6 secretion of human gastric epithelial cells, at least in part, by the stress-associated hormone norepinephrine, and provides basic data on stress and gastric cancer progression.
\end{abstract}

Key words: Norepinephrine; GES-1 cells; Interleukin-6

\section{Introduction}

The amount of literature reporting the role of psychological stress in cancer onset and development is growing. Regarding the mechanisms connecting stress and cancer progression, most of the early studies concentrated on the indirect effects of stress through immunosuppression in cancer patients (1-3). Recently, it has been reported that the stress-related hormones norepinephrine (NE) and epinephrine, especially NE, can directly induce gene expression and are involved in angiogenesis and metastasis in cancer progression in a variety of cancer cell lines (4-8), stromal cells (9), and immortalized epithelial cell lines (10). Several epidemiological studies have demonstrated that chronic stress may accelerate the progression of gastric cancer (11-13). However, the precise mechanism by which chronic stress acts in gastric cancer progression is unclear, and little is known about the effects of stress-related hormones on gastric cancer cells and gastric epithelial cells. We recently performed Bio-Plex analyses (Bio-Rad, USA) to examine the effect of NE on gastric cancer cells and gastric epithelial cells by detecting several cytokines associated with gastric cancer progression (Figure S1). These results showed the only substantial change by NE was the upregulation of interleukin-6 (IL-6) expression in GES-1 cells, an immortalized human gastric epithelial cell line. Because there are no normal human gastric epithelial cells that are commercially available, we used GES-1 cells (14) to study the effect of NE on gastric epithelial cells.

IL-6 is a pleiotropic cytokine produced by a wide variety of cells including macrophages, T cells, B cells, fibroblasts, and endothelial cells. IL-6 plays important roles in a wide range of biological activities including immune regulation, hematopoiesis, inflammation, and oncogenesis (15-17). IL-6 is also involved in gastric cancer progression, and several reports demonstrated that significant relationships existed between elevated serum IL-6 levels and tumor stages, with unfavorable

Correspondence: P. Zhang, Department of Biochemistry and Molecular Cell Biology, School of Medicine, Shanghai Jiao Tong University, Building 7-203, No. 280, South Chongqing Road, Shanghai 200025, China. E-mail: ssmuzp@139.com 
outcomes in gastric cancer patients (18-20). Interestingly, IL-6 is closely related to chronic stress. Epidemiological studies demonstrated that IL-6 was elevated in a population suffering from chronic stress $(21,22)$. Animal models also showed that stress can lead to elevated IL-6 in rats, and the sources were not immune cells (23). However, the precise mechanism of NE-induced IL-6 expression is not clear, and, furthermore, there are still no data available regarding the effect of NE on IL-6 expression in gastric epithelial cells. The present study, therefore, is aimed at investigating the effect of NE on IL-6 expression in GES-1 cells and exploring the signaling pathway and molecular mechanism involved.

\section{Material and Methods}

\section{Cell lines and culture conditions}

GES-1 (kindly provided by Dr. Zhu Zhenggang, China) is an immortalized human gastric epithelial cell line, established from fetal gastric epithelial cells after simian virus 40 (SV40) transfection (14). GES-1 cells were maintained in RPMI 1640 medium supplemented with $10 \%$ fetal bovine serum (FBS), $2 \mathrm{mM}$ L-glutamine, 100 $\mathrm{U} / \mathrm{mL}$ penicillin, and $100 \mu \mathrm{g} / \mathrm{mL}$ streptomycin at $37^{\circ} \mathrm{C}$ in a humidified atmosphere with $5 \% \quad \mathrm{CO}_{2}$. The cells were allowed to reach $80 \%$ confluency before passage. The culture medium was replenished with fresh medium every 2 or 3 days. Although the initial NE-treated experiments (Figure 1) were carried out by maintaining the cells throughout in a medium containing $10 \%$ FBS, the other protocol has been used more extensively. Cells were cultured in $10 \% \mathrm{FBS}$, and, for isoproterenol treatment, blocking, and the following NE treatments, a medium containing Advanced 1640 (Invitrogen, USA) with 1\% FBS was utilized in order to eliminate the possible influence of factors, which can be found in FBS, on the effect of NE in GES-1 cells.

To evaluate the effects of stress hormones on IL-6 secretion, $6 \times 10^{4}$ GES-1 cells were seeded into individual

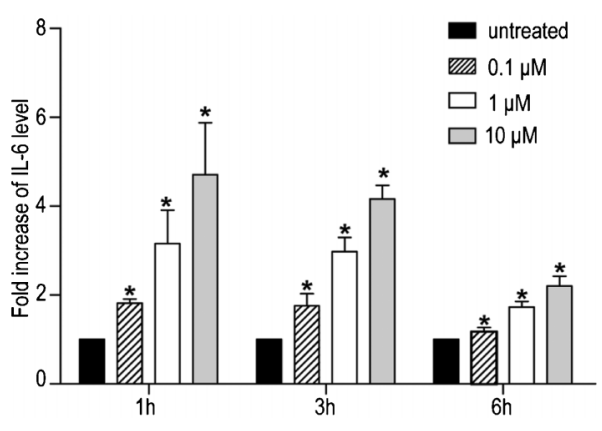

Figure 1. IL-6 production by GES-1 cells incubated with $0,0.1,1$, $10 \mu \mathrm{M}$ norepinephrine (NE). Supernatants were harvested at 1 , 3 , and $6 \mathrm{~h}$. IL- 6 levels $(\mathrm{pg} / \mathrm{mL})$ were analyzed by ELISA. Data are reported as means $\pm S E$. ${ }^{*} P<0.05$, compared to control (ANOVA followed by the Newman-Keuls post hoc test). wells of a 24-well plate. Following a 24-h incubation, triplicate cultures (wells) were stimulated by replacing the complete media containing NE or the synthetic $\beta$-adrenergic receptor agonist isoproterenol, at specific concentrations. Culture supernatants were collected at various time points, centrifuged, and stored at $-70^{\circ} \mathrm{C}$ until assayed by enzyme-linked immunoassay (ELISA). Cells were homogenized in TRIzol reagent and stored at $-70^{\circ} \mathrm{C}$ until assayed by real-time PCR.

\section{Reagents}

Phentolamine mesylate was purchased from Santa Cruz (USA), forskolin from Calbiochem (USA), KT5720 from Tocris (UK), and actinomycin D (Act D) from Beyotime Institute of Biotechnology Co. (China). Other chemicals were purchased from Sigma-Aldrich (USA).

\section{ELISA}

The concentration of IL-6 was measured using a human IL-6 ELISA Kit (Dakewe Biotech Company Limited, China) following the manufacturer's protocol. The resultant color was read at $450 \mathrm{~nm}$ using a Multiskan Spectrum microplate reader (Thermo Fisher Scientific, Finland) with the Skanlt software (version 2.4.2, Thermo Fisher Scientific). The concentration of IL-6 in a sample was determined by interpolation from a standard curve.

\section{Real-time PCR}

We utilized real-time RT-PCR on NE-treated cell lines in order to determine the effect of NE on IL-6 gene expression. Total RNA from cultured cells was isolated using TRIzol reagent following the manufacturer's instructions (Invitrogen). First-strand cDNAs were synthesized using random primers and RevertAid ${ }^{\mathrm{TM}} \mathrm{M}-\mathrm{MuLV}$ reverse transcriptase (Fermentas, Lithuania). Reactions were performed with SYBR ${ }^{\mathbb{R}}$ Premix Ex Taq ${ }^{\mathrm{TM}}$ and the specific primers, following the manufacturer's instructions (TaKaRa BIO Inc., China). Levels of IL-6 mRNA were measured and amplified using the 7300 real-time PCR system (Applied Biosystems, USA). The cycler conditions were as follows: incubation for $30 \mathrm{~s}$ at $95^{\circ} \mathrm{C}$, followed by $5 \mathrm{~s}$ at $95^{\circ} \mathrm{C}$, and $31 \mathrm{~s}$ at $60^{\circ} \mathrm{C}$ for 40 cycles. The levels of expression of IL-6 mRNA in each sample were normalized to the GAPDH mRNA levels. The relative expression of mRNA species was calculated using the $2^{-\Delta \Delta C t}$ method. All primer sequences span across two adjacent exons of the target genes and are thus specific for mRNAs, as follows: IL-6 forward primer: 5'-AACCTGAACCTTCCA AAGATGG-3'; IL-6 reverse primer: 5'-TCTGGCTTGTTC CTCACTACT-3'; GAPDH forward primer: 5'-TGTTGC CATCAATGACCCCTT-3'; GAPDH reverse primer: 5'CTCCACGACGTACTCAGCG-3'.

In order to elucidate the mechanism in the NEdependent regulation of IL- 6 mRNA levels in GES-1 cells, the effect of Act $D$, an inhibitor of de novo transcription, was assessed on mRNA levels. GES-1 cells were grown 
in the presence of $5 \mu \mathrm{g} / \mathrm{mL}$ Act $D$ and $10 \mu \mathrm{M} \mathrm{NE}$ for $1 \mathrm{~h}$. Total RNA was isolated, and the levels of IL-6 mRNA were measured using real-time PCR as described earlier.

\section{Assessment of signaling pathways}

In order to examine the signaling pathway involved in NE-induced IL-6 expression, we treated GES- 1 cells with a variety of agonists and antagonists. The $\beta$-adrenoreceptor antagonist propranolol $(10 \mu \mathrm{M})$ and the protein kinase $A$ (PKA) inhibitor KT5720 $(10 \mu \mathrm{M})$ were added to the cell cultures $3 \mathrm{~h}$ before adding $10 \mu \mathrm{M} \mathrm{NE}$. The $\alpha$-adrenoreceptor antagonist phentolamine $(10 \mu \mathrm{M})$ was added to the cell cultures $1 \mathrm{~h}$ prior to the addition of $10 \mu \mathrm{M} \mathrm{NE}$. After blocking, the media was replaced with 1\% FBS Advanced 1640 containing $10 \mu \mathrm{M} \mathrm{NE}$ and the cells continued to incubate for $3 \mathrm{~h}$. GES- 1 cells were treated with the $\beta$-adrenoreceptor agonist isoproterenol $(10 \mu \mathrm{M})$ and the adenylate cyclase agonist forskolin $(10 \mu \mathrm{M})$. Conditioned medium was collected after a 3-h incubation, centrifuged at $300 \mathrm{~g}$ for $10 \mathrm{~min}$, and stored at $-70^{\circ} \mathrm{C}$ until tested for the presence of IL- 6 by ELISA.

\section{Plasmid construction, $5^{\prime}$-deletion constructs, and site-directed mutagenesis}

Genomic DNA was isolated from GES-1 cells using a Tianamp Genomic DNA kit (Tiangen, Biotech, China). A 2092-bp PCR fragment corresponding to the promoter region of IL-6 ( -2035 to $+53 \mathrm{bp}$ ) was generated using the upstream primer: 5'-GTGGTACCCCCGTTTTATAGG-3' and the downstream primer: 5'-CTGGAGGGGAGA TAGAGCTTC-3' in a PCR using PrimerSTAR HS ${ }^{\circledR}$ DNA polymerase (TaKaRa BIO Inc.). The 2092-bp fragment was subcloned (5'-Kpnl, 3'-Xhol) into a pGL3 basic luciferase reporter gene vector (Promega, USA) and sequenced for orientation and fidelity. This plasmid served as the source of inserts for further plasmid constructions.

To make the 5 '-deletion constructs, shorter fragments were generated using new upstream primers, and the common downstream primer was the same as the reverse primer of the 2092-bp fragment. From this parental construct, plL-6P-luc1184 and three 5'-deletion mutants were generated by using the upstream primer as shown in Table 1. plL-6P-luc1184 contains the full-length sequence (24) of the IL-6 promoter (from $1173 \mathrm{bp}$ upstream of the transcription start site to $+11 \mathrm{bp}$ ). plL-6P-luc710 contains the four consensus sequences for the transcription factors activating-protein-1 (AP-1), cAMP-responsive element binding protein (CREB), CCAAT-enhancer binding protein- $\beta$ (C/EBP- $\beta)$, and nuclear factor $\kappa$-light-chain-enhancer of activated $B$ cells (NF- $\kappa B$ ) as plL-6P-luc1184. The other two 5'-deletion mutants were deleted fragments containing the consensus sequences for transcription factors C/EBP- $\beta$ and NF- $\kappa B$ (plL-6P-luc204) or NF- $\kappa B$ (plL-6P-luc107). DNA sequence analysis confirmed these sequences.

Within plL-6P-luc1184, critical nucleotides necessary for transcription factor (AP-1, CREB, C/EBP- $\beta$, and NF- $\kappa B$ ) binding to the four consensus sites were inactivated by using a QuikChange Lightning site-directed mutagenesis kit (Agilent Technology, USA) and are listed in Table 1. These mutations have previously been shown to inactivate the described consensus sequences (25). All mutant clones designated as pIL-6P-AP1-m, plL-6P-CREB-m, pIL-6P-C/EBP-m, and pIL-6P-NF $\kappa B-m$ were verified by DNA sequencing.

\section{Cell transfection and luciferase assays}

Cell transfection was performed according to the manufacturer's instruction using the Lipofectamine ${ }^{\mathrm{TM}}$ 2000 reagent (Invitrogen). Briefly, the cells were seeded onto 24-well plates at a density of $6 \times 10^{4}$ cells/well and incubated at $37^{\circ} \mathrm{C}$ overnight. For each transfection sample, cells were transfected with $0.1 \mu \mathrm{g}$ luciferase plasmid and $1 \mathrm{ng}$ pRL-TK reporter plasmid using $2 \mu \mathrm{L}$ Lipofectamine $^{\mathrm{TM}} 2000$.

Sixteen hours following transfection, the cells were treated with $10 \mu \mathrm{M} \mathrm{NE}$ for $3 \mathrm{~h}$. After treatment, a dual

Table 1. Sequences of upstream primers used in the plasmid constructions and site-directed mutagenesis.

\begin{tabular}{ll}
\hline Plasmids & \multicolumn{1}{c}{ Upstream primers } \\
\hline Plasmid constructions & \\
plL-6P-luc1184 & $5^{\prime}$-gtggtaccaaggatcctcctgcaag-3' \\
plL-6P-luc710 & $5^{\prime}$-atggtacctctaagtgggctgaag-3' \\
pIL-6P-luc204 & $5^{\prime}$-gtggtaccccctagttgtgtcttgc-3' \\
pIL-6P-luc107 & $5^{\prime}$-gtggtaccctcaccctccaacaaag-3' \\
Site-directed mutagenesis & \\
pIL-6P-AP1-m & $5^{\prime}$-caagacatgccaaagtgctgCgtcGctaataaaag-3' \\
pIL-6P-CREB-m & $5^{\prime}$-gccatgctaaaggacCtcGcattgcacaatcttaataagg-3' \\
pIL-6P-C/EBP-m & $5^{\prime}$-gccatgctaaaggacgtcacaGCgGacaatcttaataaggtttcc-3' \\
pIL-6P-NFKB-m & $5^{\prime}$-gatttatcaaatgtgggatttGcGcatgagtctcaatattagag-3' \\
\hline
\end{tabular}

The regions of capitalized oligonucleotides indicate the positions that carry mutations. 
luciferase assay (Promega) was performed. In brief, cells were lysed with passive lysis buffer, and $20 \mu \mathrm{L}$ aliquots of each sample were assayed on an amber 96-well plate by a luminometer (NOVOstar, Germany). As an internal control for transfection efficiency, pRL-TK, the expression plasmid encoding Renilla luciferase driven by the thymidine kinase promoter, was used ( $1 \mathrm{ng} /$ well). Firefly and Renilla luciferase have distinct substrate properties, and thus the activities of both enzymes can be assessed in the same sample using two substrates sequentially. Each transfection was performed in triplicate and in a minimum of three independent experiments.

\section{Statistical analysis}

Statistically significant differences between groups were determined by ANOVA using GraphPad Prism v5.0 (GraphPad Software Inc., USA). $\mathrm{P}<0.05$ was considered to indicate a statistically significant difference. When a significant main effect of drug treatment was identified $(P<0.05)$, the Newman-Keuls post hoc test was used to compare groups.

\section{Results}

NE stimulation increases IL-6 protein in GES-1 cells GES-1 cells were stimulated with increasing concentrations of NE, and the supernatants were assayed for IL- 6 by ELISA as shown in Figure 1. Using ANOVA and the Newman-Keuls post hoc test, we demonstrated that an NE dose-dependent and time-dependent increase of IL-6 expression in culture supernatants of GES-1 cells with the $1 \mathrm{~h}$ treatment yielded the greatest effect. Treatment of GES-1 cells with 1 and $10 \mu \mathrm{M}$ NE for $1 \mathrm{~h}$ produced a $3.15 \pm 1.31$ and $4.71 \pm 2.02$ fold increase, respectively. The overall IL- 6 induction by $10 \mu \mathrm{M}$ NE in 3 and $6 \mathrm{~h}$ differed significantly from the control values, but the fold increase was less than that produced in $1 \mathrm{~h}$ by $10 \mu \mathrm{M} \mathrm{NE}(4.16 \pm 0.53$ fold in $3 \mathrm{~h}$ and $2.21 \pm 0.38$ fold in $6 \mathrm{~h}$ ). Because the mean basal production of IL-6 by GES1 cells at $1 \mathrm{~h}$ was $9.47 \pm 0.87 \mathrm{pg} / \mathrm{mL}$, which was very near the lower detection limit of the ELISA kit, we chose the time point of $3 \mathrm{~h}$ and $10 \mu \mathrm{M} \mathrm{NE}$ in the following experimental protocols.

\section{NE stimulation increases IL-6 mRNA in GES-1 cells}

To further elucidate the mechanism involved in the induction of IL-6 expression in GES-1 cells, we examined the effect of exposure to NE on the transcription of IL-6 expression. GES-1 cells were stimulated with $10 \mu \mathrm{M} \mathrm{NE}$, and IL-6 mRNA levels were quantified using real-time RTPCR at multiple time points ranging from $15 \mathrm{~min}$ to $6 \mathrm{~h}$. The level of IL- 6 mRNA was normalized against GAPDH mRNA levels. As shown in Figure 2A, treatment of GES-1 cells with NE resulted in a significant increase of IL-6 mRNA levels, which peaked after $1 \mathrm{~h}$, decreased thereafter, and returned to baseline within $6 \mathrm{~h}$. However, for
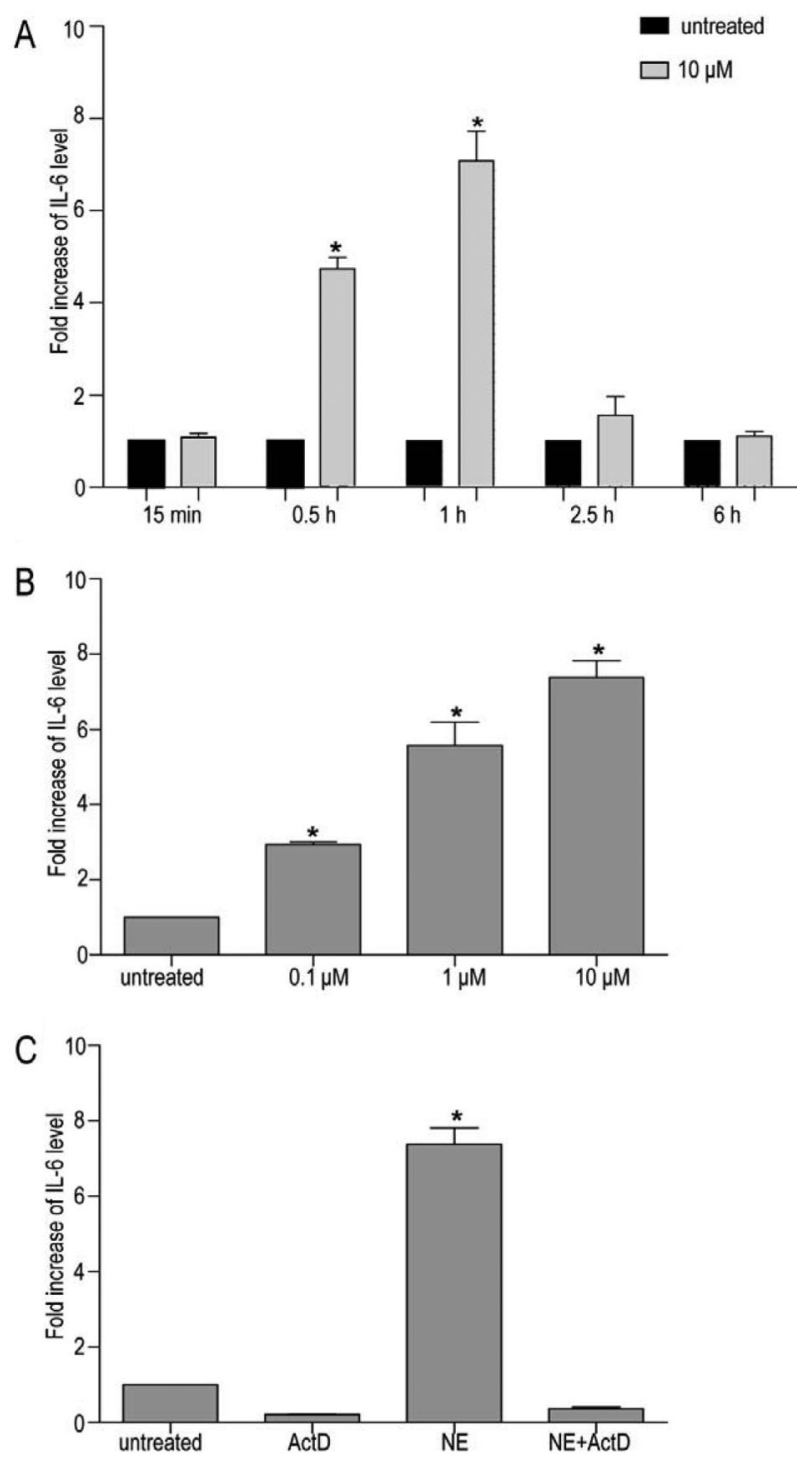

Figure 2. Norepinephrine (NE) increases IL-6 mRNA in GES-1 cells. $A$, Pattern of NE-stimulated IL- 6 mRNA levels in GES-1 cells. Levels of mRNA in GES-1 cells were measured using realtime PCR after treatment with $10 \mu \mathrm{M} \mathrm{NE}$ for $15 \mathrm{~min}, 0.5 \mathrm{~h}, 1 \mathrm{~h}$, $2.5 \mathrm{~h}$, and $6 \mathrm{~h}$. Peak expression of IL-6 mRNA was observed at $1 \mathrm{~h}$ after treatment and decreased thereafter. $B$, Dose-response pattern of NE upregulates IL-6 mRNA levels in GES-1 cells. Levels of mRNA in GES-1 cell were measured using real-time PCR after treatment with $0,0.1,1$, and $10 \mu \mathrm{M}$ NE for $1 \mathrm{~h}$. Peak expression of IL-6 mRNA was observed after $10 \mu \mathrm{M} N E$ treatment. $C$, The NE-dependent up-regulation of IL-6 mRNA levels in GES-1 cells was mainly through the stimulation of transcription. Real-time PCR assay measuring IL-6 mRNA levels in GES-1 after treatment with $5 \mu \mathrm{g} / \mathrm{mL}$ actinomycin $\mathrm{D}$ (Act D), $10 \mu \mathrm{M}$ NE, or NE + Act D for $1 \mathrm{~h}$. Data are from 2-3 independent tests with triplicates. Data are reported as mean $\pm \mathrm{SE}$ fold increase of untreated control levels. ${ }^{*} \mathrm{P}<0.05$, compared to untreated control (ANOVA). 
cells exposed to specified doses of NE, IL-6 mRNA levels showed a dose-dependent increase (Figure 2B).

Co-treatment of GES-1 cells with $5 \mu \mathrm{g} / \mathrm{mL}$ Act $D$ and $10 \mu \mathrm{M} N E$ efficiently inhibited the NE-dependent upregulation of IL-6 mRNA levels (Figure $2 \mathrm{C}$ ). This suggests that the NE-dependent upregulation of the IL-6 protein in GES1 cells is mainly due to the stimulation of de novo transcriptional activity of the IL-6 gene.

\section{Effect of NE on IL-6 upregulation is mediated by the $\beta$-adrenoreceptor-adenylyl cyclase-cAMP-PKA signaling pathway}

To determine whether the effect of NE on IL-6 expression is transduced by ligation of the $\beta$-adrenoreceptor, GES-1 cells were incubated in the presence of the $\beta$-antagonist propranolol $(10 \mu \mathrm{M})$ prior to $10 \mu \mathrm{M} \mathrm{NE}$ stimulation. As shown in Figure 3A, propranolol completely abolished NE-induced IL- 6 expression. In contrast, the $\alpha$ adrenoreceptor antagonist phentolamine $(10 \mu \mathrm{M})$ had no effect on the ability of NE to induce IL-6 production (Figure $3 \mathrm{~B})$. Treatment with the $\beta$-adrenoreceptor agonist isoproterenol $(10 \mu \mathrm{M})$ resulted in significant stimulation of IL-6 gene expression, supporting the hypothesis that ligation of $\beta$-adrenoreceptors is involved in the observed NE-dependent effect (Figure 3C).

To determine whether activation of the adenylyl cyclase-cAMP-PKA signaling pathway is capable of IL-6 upregulation, GES-1 cells were stimulated in the presence of the adenylyl cyclase activator forskolin $(10 \mu \mathrm{M})$. Forskolin increased IL-6 expression to levels similar to those observed in NE-treated cultures (Figure 3D). To determine whether the effects of NE on IL-6 expression
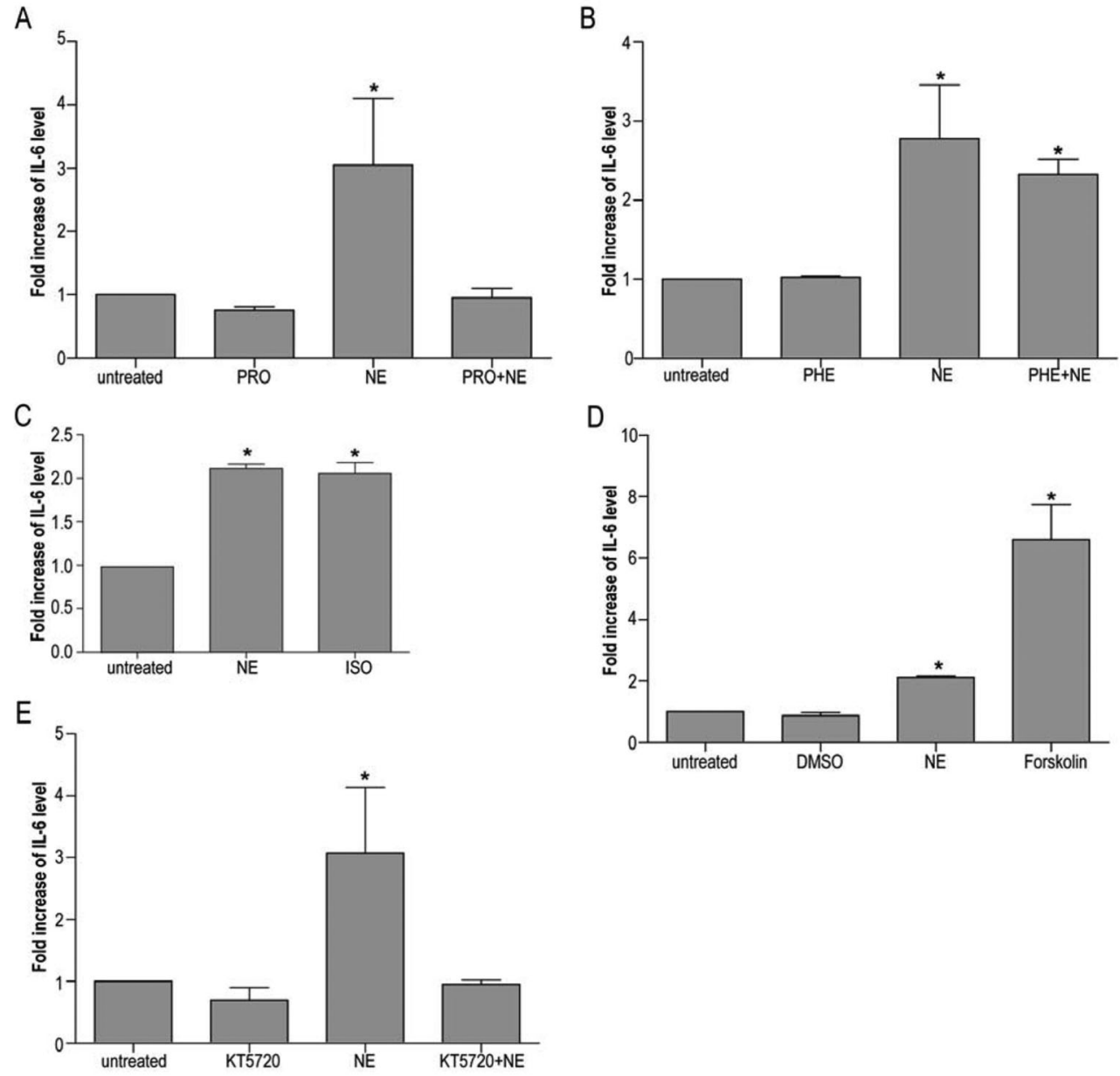

Figure 3. Assessment of the role of $\beta$-adrenergic receptors-cAMP-PKA pathway in norepinephrine (NE)-induced IL-6 expression of GES1 cells. $A$, ELISA assay measuring IL-6 after treatment with $10 \mu \mathrm{M} \mathrm{NE}, 10 \mu \mathrm{M}$ propranolol (PRO), $10 \mu \mathrm{M}$ NE plus PRO (PRO + NE). B, ELISA assay measuring IL-6 after treatment with $10 \mu \mathrm{M} \mathrm{NE}, 10 \mu \mathrm{M}$ phentolamine (PHE), $10 \mu \mathrm{M}$ NE plus PHE (PHE + NE). C, ELISA assay measuring IL-6 after treatment with $10 \mu \mathrm{M} \mathrm{NE}, 10 \mu \mathrm{M}$ isoproterenol (ISO). D, ELISA assay measuring IL-6 after treatment with DMSO, $10 \mu \mathrm{M}$ NE, $10 \mu \mathrm{M}$ forskolin. E, ELISA assay measuring IL-6 after treatment with $10 \mu \mathrm{M} \mathrm{NE}, 10 \mu \mathrm{M}$ KT5720 and $10 \mu \mathrm{M}$ NE plus $10 \mu \mathrm{M}$ KT5720 (KT5720 + NE). Data are reported as means $\pm \mathrm{SE}$. ${ }^{*} \mathrm{P}<0.05$, compared to control (ANOVA). 
were mediated by activation of PKA, GES-1 cells were incubated in the presence of the PKA inhibitor KT5720 $(10 \mu \mathrm{M})$ prior to NE stimulation. PKA blockade strongly inhibited the effect of NE on IL-6 expression (Figure 3E), reducing IL-6 expression to levels that were statistically indistinguishable from control cultures. Thus, activation of the PKA signaling cascade via cell surface $\beta$-adrenoreceptor appears to mediate the effect of NE on IL-6 expression.

\section{IL-6 promoter is inducible by NE in GES-1 cells}

In order to identify cis-regulatory sequences that were responsible for upregulation of IL-6 expression by NE, we generated the full-length IL-6 promoter (24) construct (1184 bp upstream of the transcription start site), designated as plL-6P-luc1184, and the following three deletion mutants of plL-6P-luc1184 as follows: i) plL-6P-luc710, containing four cis-acting elements; ii) plL-6P-luc204, deficient in a known AP-1 consensus sequence; and iii) plL-6P-luc107, deficient in both a known AP-1 and a known CREB consensus sequence (Figure 4A).

As demonstrated in Figure 4B, plL-6P-luc710 has the same basal activity as plL-6P-luc1184, and both can be induced by $N E$ with a $210 \pm 15.6 \%$ increase $(P<0.05)$. However, the IL-6 induction by NE in GES-1 cells transfected with plL-6P-luc204 and plL-6P-luc107 did not differ significantly from control values. This suggests that the NE-responsive cis-acting elements are located from -699 to +11 bp of the IL- 6 promoter.

\section{AP-1 and CREB binding sites are required for induction of the IL- 6 gene by NE}

To examine which regulatory elements in the IL-6 promoter are responsive to NE, we introduced 2- to 3-bp mutations into the core regions of the transcription factor (AP-1, CREB, C/EBP- $\beta$, and NF- $\kappa$ B) binding sites within the context of the 1.2-kb IL-6 promoter as outlined in Figure $5 \mathrm{~A}$, with the intention to completely abolish the interaction between individual trans-acting factors and their cognate recognition sequences. In contrast to deletion studies, this approach should enable us to identify the contribution of single regulatory elements to gene activation in the context of the full-length promoter.

As shown in Figure 5B, when AP-1 and CREB binding sites were mutated, the basal promoter activity was reduced to $31 \pm 3.3 \%$ and $78.6 \pm 10.3 \%$ of the wild-type promoter, respectively. Also, there was no statistical difference between GES-1 cells transfected with pIL-6P. CREB-m and plL-6P-luc1184, while there was a statistical difference between GES-1 cells transfected with pIL-6PAP1-m and plL-6P-luc1184. However, mutations of the $\mathrm{AP}-1$ and $\mathrm{CREB}$ binding sites can both diminish inducibility by NE. Therefore, it can be concluded that AP-1 and CREB binding sites were found to be functionally required for inducibility of the IL-6 promoter by NE.

In contrast, as shown in Figure $5 \mathrm{~B}$, mutation of the $\mathrm{C} / \mathrm{EBP}-\beta$ and $\mathrm{NF}-\kappa \mathrm{B}$ binding sites did not significantly affect inducibility by NE, and basal promoter activity was reduced to $79.4 \pm 16.7 \% \quad(P>0.05)$ and $46.1 \pm 15 \%$ $(\mathrm{P}<0.05)$ of the wild-type promoter, respectively. These data indicate that $\mathrm{C} / \mathrm{EBP}-\beta$ and $\mathrm{NF}-\kappa \mathrm{B}$ binding sites are not essential for NE inducibility.

Briefly, AP-1, CREB, C/EBP- $\beta$, and NF- $\kappa B$ binding sites in the IL- 6 promoter are all involved in the basal transciption of IL-6. AP-1 and CREB binding sites are
A

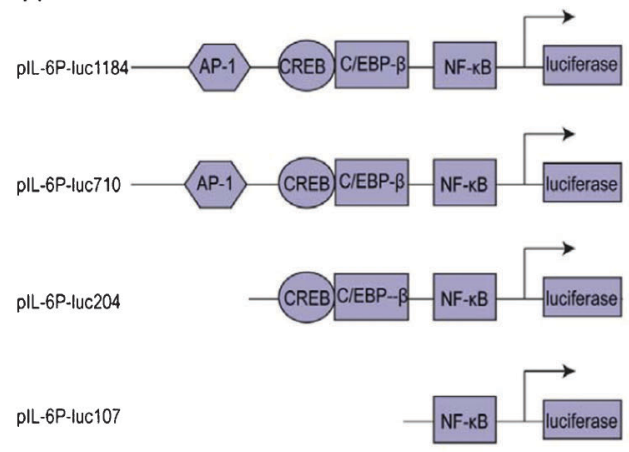

B

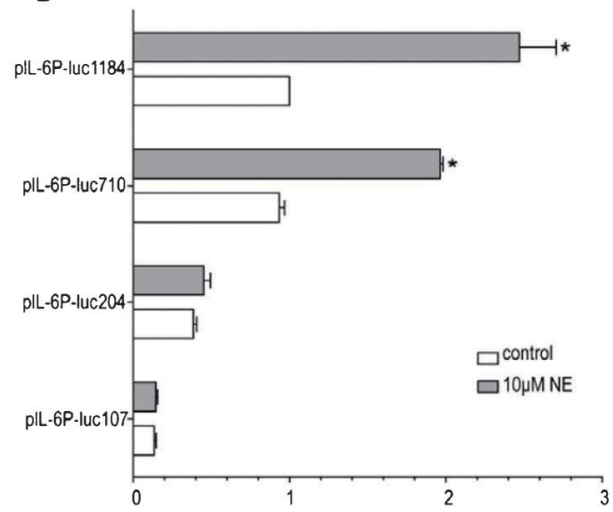

Figure 4. Deletion analysis of IL-6 promoter constructs by $10 \mu \mathrm{M}$ norepinephrine (NE) in GES-1 cells. $A$, Structures of the four pIL-6Pluc constructs are shown schematically. The configuration of the promoter region of the human IL- 6 gene is illustrated at the top, in which cis-acting elements so far identified are boxed. AP-1 (activating protein-1), CREB (cAMP-responsive element binding protein), $\mathrm{C} / \mathrm{EBP}-\beta$ (CCAAT-enhancer binding protein- $\beta$ ), and NF- $\mathrm{kB}$ (nuclear factor $\kappa$-light-chain-enhancer of activated $\mathrm{B}$ cells) binding sites. $B$, A series of IL-6-luciferase reporter constructs were transfected into GES-1 cells. After overnight incubation, GES-1 cells were treated with $10 \mu \mathrm{M} \mathrm{NE}$ for another $3 \mathrm{~h}$. The cells were lysed and assayed for luciferase activity. Firefly luciferase activity was normalized to cotransfected control Renilla luciferase driven by a TK promoter and expressed as a fold change relative to untreated wild-type IL-6 promoter (plL-6P-luc1184). Data are reported as means \pm SE of 3 independent experiments with triplicate measurements. ${ }^{*} P<0.05$, compared to untreated wild-type IL-6 promoter (plL-6P-luc1184) by ANOVA. 

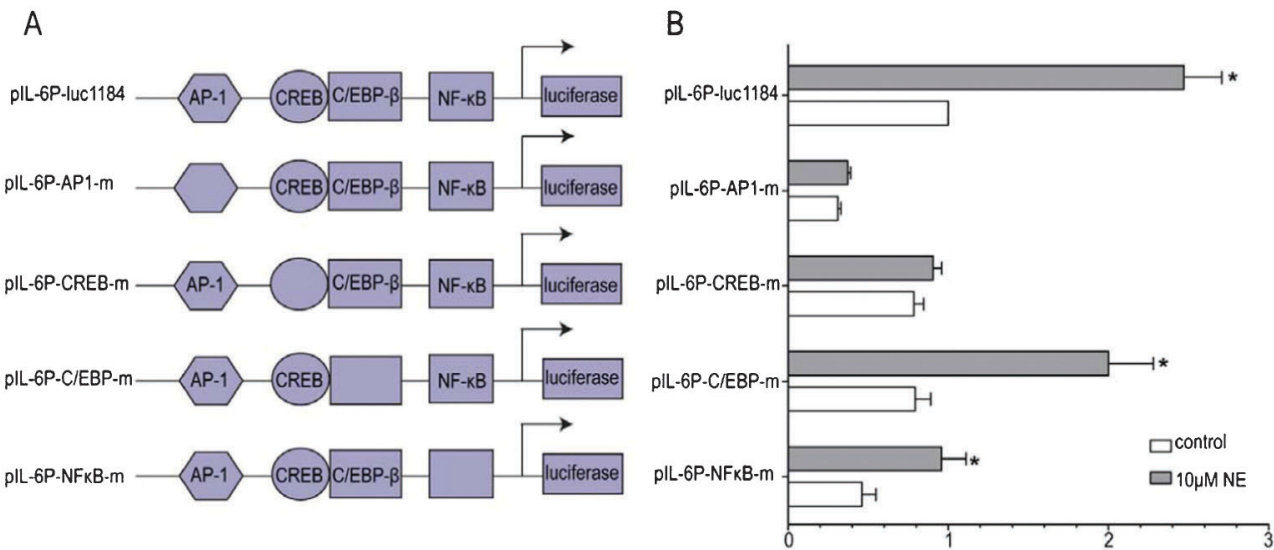

Figure 5. Site-directed mutations within the four elements affected the IL-6 promoter activity in response to $10 \mu \mathrm{M}$ norepinephrine (NE) in GES-1 cells. $A$, Schematic structure of site-directed mutations within the four transcriptional factor binding sites (AP-1, CREB, C/EBP- $\beta$, and NF-кB elements) of IL- 6 promoter. $B$, Mutational analysis of IL- 6 promoter activity in response to NE. GES-1 cells were transfected with luciferase expression vectors driven by the human IL-6 promoter or variants bearing point mutations in the AP-1 (activating protein-1), CREB (CAMP-responsive element binding protein), C/EBP- $\beta$ (CCAAT-enhancer binding protein- $\beta$ ), and NF- $\kappa B$ (nuclear factor $\kappa$-light-chain-enhancer of activated B cells) binding sites. Following transfection, cells were cultured for $3 \mathrm{~h}$ in $10 \mu \mathrm{M}$ NE. The cells were lysed and assayed for luciferase activity. Firefly luciferase activity was normalized to co-transfected control Renilla luciferase driven by a TK-promoter and expressed as a fold change relative to untreated wild-type IL-6 promoter (pIL-6P-luc1184). Data are reported as means \pm SE of 3 independent experiments with triplicate measurements. ${ }^{*} \mathrm{P}<0.05$, compared to untreated wild-type IL6 promoter (plL-6P-luc1184) by ANOVA.

involved in NE-induced IL-6 expression, whereas C/EBP$\beta$ and $N F-\kappa B$ binding sites are not.

\section{Discussion}

In the present study, we found that the stress-related hormone NE can induce IL-6 expression in GES-1 cells and does so via the $\beta$-adrenoreceptor-adenylyl cyclaseCAMP-PKA signaling cascade. Moreover, we demonstrated that NE induces IL-6 expression mainly at the transcriptional level. Further evidence demonstrated that NE-induced IL-6 expression needs AP- 1 and CREB binding sites in the IL- 6 promoter.

We first examined the effect of NE on IL-6 expression of human gastric epithelial cells. Because normal human gastric epithelial cells are not commercially available, we used the immortalized human gastric epithelial cell line GES-1. The results demonstrated that NE induced IL-6 expression in GES-1 cells. Because IL-6 is a pleiotropic cytokine closely related to chronic stress, regulation of IL- 6 by stress-related hormones has been suggested previously $(7,26)$. Upregulation of IL-6 is also associated with gastric diseases; therefore, a better understanding of the molecular regulation of IL-6 production by NE in gastric epithelial cells has important clinical implications. However, until now, the precise mechanism of IL-6 induction after exposure to NE in gastric epithelial cells has not been explored. Therefore, we further examined the mechanism involved in NE-induced IL-6 expression in GES-1 cells.
In the classical NE signaling pathway, ligation of the cell surface $\beta$-adrenoreceptor activates adenylyl cyclase, which triggers increased synthesis of CAMP and thereby activates the CAMP-dependent kinase PKA, leading to the phosphorylation of downstream molecules. In our study, propranolol, the $\beta$-adrenoreceptor antagonist, completely abrogated the effect of NE on IL-6 expression, while the $\alpha$-adrenoreceptor antagonist phentolamine had no effect. The $\beta$-adrenoreceptor agonist isoproterenol mimicked the effect of NE on IL-6 expression. Given that GES-1 cells express both $\beta_{1}$ - and $\beta_{2}$-adrenoreceptors by Western blot (see Figure S2), it is concluded that $\beta$-adrenoreceptor is involved in NE-induced IL-6 expression while $\alpha$-adrenoreceptor is not. Forskolin, an adenylyl cyclase activator, mimicked the effect of NE on IL-6 expression, and the PKA inhibitor KT5720 completely abrogated the effect of NE on IL-6 expression. These results suggest that the classical CAMP-PKA signaling pathway mediates NE-induced IL-6 expression in GES-1 cells.

IL-6 secretion and mRNA increased after NE stimulation of GES- 1 cells. The increase of IL- 6 transcripts was completely blocked if the cells were co-treated with the transcriptional inhibitor Act D and NE, indicating IL-6 gene regulation at the transcriptional level in response to NE.

In general, transcriptional induction is due to the specific binding of activated transcription factors at functional DNA recognition elements within accessible regulatory regions of the inducible genes. To determine the effect of NE on transcriptional regulation of IL-6 gene expression, we used a transient transfection assay and 
reporter constructs with the luciferase gene placed under the transcriptional control of the human IL-6 promoter. The deletion analysis of pIL-6P-luc1184 showed the NEresponsive cis-acting elements are located from -699 to $+11 \mathrm{bp}$ of the IL-6 promoter. This result is in agreement with other reports that this region contains specific sequence motifs bound by multiple cis-activating transcription factors including NF- $\mathrm{NB}, \mathrm{AP}-1, \mathrm{C} / \mathrm{EBP}-\beta$, and CREB $(24,25,27,28)$.

As shown above, NE induced IL-6 expression through the classical CAMP-PKA signaling pathway. The classical example for a cAMP-regulated transcription factor is CREB, which becomes activated upon phosphorylation by cAMP-dependent PKA and could potentially bind to the CREB protein binding site $(29,30)$. However, transcription factors binding to AP-1 (31), C/EBP- $\beta$ (32), and NF- $\kappa B$ (33) sites are also considered candidates for the transmission of cAMP-mediated signals to the transcriptional machinery. In order to further identify NE-induced cAMP-responsive elements in the IL-6 promoter, we therefore studied the effect of $\mathrm{NE}$ on the mutated individual AP-1, CREB, C/EBP- $\beta$, and NF- $\kappa B$ binding sites in the IL-6 promoter-reporter gene constructs in transiently transfected GES-1 cells. The results indicate that AP-1 and CREB binding sites are essential for NE induction of IL-6 expression in GES-1 cells, while all four binding sites may be involved in basal transcription of the IL-6 gene. Our finding is in concert with a prior study that has implicated AP-1 and CREB activation in the regulation of IL-6 expression induced by NE or isoproterenol in cardiomyocytes (26). Similarly, AP-1 activation via PKA and p38 MAPK (p38 mitogen-activated protein kinase) is reported to contribute to IL-6 induction in osteoblastic cells under $\beta$-adrenergic stimulation (34). In contrast, it has been demonstrated that only the C/EBP- $\beta$ (NF-IL-6) motif

\section{References}

1. Ben-Eliyahu S, Yirmiya R, Liebeskind JC, Taylor AN, Gale RP. Stress increases metastatic spread of a mammary tumor in rats: evidence for mediation by the immune system. Brain Behav Immun 1991; 5: 193-205, doi: 10.1016/08891591(91)90016-4.

2. Ben-Eliyahu S, Shakhar G, Page GG, Stefanski V, Shakhar K. Suppression of NK cell activity and of resistance to metastasis by stress: a role for adrenal catecholamines and $\beta$-adrenoceptors. Neuroimmunomodulation 2000; 8: 154-164, doi: $10.1159 / 000054276$

3. Reiche EM, Nunes SO, Morimoto HK. Stress, depression, the immune system, and cancer. Lancet Oncol 2004; 5 : 617-625, doi: 10.1016/S1470-2045(04)01597-9.

4. Yang EV, Donovan EL, Benson DM, Glaser R. VEGF is differentially regulated in multiple myeloma-derived cell lines by norepinephrine. Brain Behav Immun 2008; 22: 318-323, doi: 10.1016/j.bbi.2007.09.010.

5. Lutgendorf SK, Cole S, Costanzo E, Bradley S, Coffin J, Jabbari S, et al. Stress-related mediators stimulate vascular is involved in NE-mediated IL-6 expression (7) in human ovarian carcinoma cells. Although the NF- $\mathrm{KB}$ binding site is reported to be involved in many stimuli $(28,35,36)$, it is not essential for NE-mediated IL-6 expression in GES-1 cells. These studies suggest that, although NE can induce IL-6 expression in various cell types, the roles of these transcription factors in NE-induced IL-6 expression are shown to be cell specific.

In conclusion, the present study demonstrated that stress-related hormone NE induced IL-6 expression in GES-1 cells. The induction was via the $\beta$-adrenergic receptor-cAMP-PKA pathway and mainly at the transcriptional level. Although AP-1, CREB, C/EBP- $\beta$, and NF-кB binding sites are all required in the basal transcription of IL-6, only AP-1 and CREB binding sites in the IL-6 promoter were required for NE-induced IL- 6 expression. The present study suggests that chronic stress may increase IL-6 secretion of human gastric epithelial cells, at least in part, by the stress-associated hormone NE, and provides basic data on stress and gastric cancer progression.

\section{Supplementary Material}

Click here to view [pdf]

\section{Acknowledgments}

GES-1 cells were kindly provided by Dr. Zhu Zhenggang, Shanghai Key Laboratory of Gastric Neoplasms, Ruijin Hospital, Shanghai Jiao Tong University School of Medicine. Research supported by grants from the Leading Academic Discipline Project, Shanghai Municipal Education Commission (\#J50201) and the Natural Science Foundation of China (grant \#31000662).

endothelial growth factor secretion by two ovarian cancer cell lines. Clin Cancer Res 2003; 9: 4514-4521.

6. Bernabe DG, Tamae AC, Biasoli ER, Oliveira SH. Stress hormones increase cell proliferation and regulates interleukin-6 secretion in human oral squamous cell carcinoma cells. Brain Behav Immun 2011; 25: 574-583, doi: 10.1016/ j.bbi.2010.12.012.

7. Nilsson MB, Armaiz-Pena G, Takahashi R, Lin YG, Trevino $\mathrm{J}$, Li $\mathrm{Y}$, et al. Stress hormones regulate interleukin-6 expression by human ovarian carcinoma cells through a Src-dependent mechanism. J Biol Chem 2007; 282: 2991929926, doi: 10.1074/jbc.M611539200.

8. Yang EV, Kim SJ, Donovan EL, Chen M, Gross AC, Webster Marketon $\mathrm{JI}$, et al. Norepinephrine upregulates VEGF, IL-8, and IL-6 expression in human melanoma tumor cell lines: implications for stress-related enhancement of tumor progression. Brain Behav Immun 2009; 23: 267-275, doi: 10.1016/j.bbi.2008.10.005

9. Lutgendorf SK, Lamkin DM, Jennings NB, Arevalo JM, 
Penedo F, DeGeest $\mathrm{K}$, et al. Biobehavioral influences on matrix metalloproteinase expression in ovarian carcinoma. Clin Cancer Res 2008; 14: 6839-6846, doi: 10.1158/10780432.CCR-08-0230.

10. Chan C, Lin HJ, Lin J. Stress-associated hormone, norepinephrine, increases proliferation and IL-6 levels of human pancreatic duct epithelial cells and can be inhibited by the dietary agent, sulforaphane. Int J Oncol 2008; 33: 415-419.

11. Watabe K, Nishi M, Miyake H, Hirata K. Lifestyle and gastric cancer: a case-control study. Oncol Rep 1998; 5: 11911194.

12. Jansson $\mathrm{C}$, Johansson $\mathrm{AL}$, Jeding K, Dickman PW, Nyren O, Lagergren J. Psychosocial working conditions and the risk of esophageal and gastric cardia cancers. Eur J Epidemiol 2004; 19: 631-641, doi: 10.1023/B:EJEP.0000036806.51918.40.

13. Oh DY, Choi KS, Shin HR, Bang YJ. Public awareness of gastric cancer risk factors and disease screening in a high risk region: a population-based study. Cancer Res Treat 2009; 41: 59-66, doi: 10.4143/crt.2009.41.2.59.

14. Ke $Y$, Ning T, Wang B. Establishment and characterization of a SV40 transformed human fetal gastric epithelial cell line-GES-1. Zhonghua Zhong Liu Za Zhi 1994; 16: 7-10.

15. Hodge DR, Hurt EM, Farrar WL. The role of IL- 6 and STAT3 in inflammation and cancer. Eur $J$ Cancer 2005; 41: 25022512, doi: 10.1016/j.ejca.2005.08.016.

16. Bromberg J, Wang TC. Inflammation and cancer: IL-6 and STAT3 complete the link. Cancer Cell 2009; 15: 79-80, doi: 10.1016/j.ccr.2009.01.009.

17. Kishimoto T. IL-6: from its discovery to clinical applications. Int Immunol 2010; 22: 347-352, doi: 10.1093/intimm/dxq030.

18. Kai H, Kitadai $\mathrm{Y}$, Kodama M, Cho S, Kuroda $\mathrm{T}$, Ito M, et al. Involvement of proinflammatory cytokines IL-1 $\beta$ and IL-6 in progression of human gastric carcinoma. Anticancer Res 2005; 25: 709-713.

19. Heikkila K, Ebrahim S, Lawlor DA. Systematic review of the association between circulating interleukin-6 (IL-6) and cancer. Eur J Cancer 2008; 44: 937-945, doi: 10.1016/ j.ejca.2008.02.047.

20. Tsujimoto H, Ono S, Ichikura T, Matsumoto $\mathrm{Y}$, Yamamoto J, Hase K. Roles of inflammatory cytokines in the progression of gastric cancer: friends or foes? Gastric Cancer 2010; 13 : 212-221, doi: 10.1007/s10120-010-0568-x.

21. Kiecolt-Glaser JK, Preacher KJ, MacCallum RC, Atkinson C, Malarkey WB, Glaser R. Chronic stress and age-related increases in the proinflammatory cytokine IL-6. Proc Natl Acad Sci U S A 2003; 100: 9090-9095, doi: 10.1073/pnas. 1531903100.

22. Costanzo ES, Lutgendorf SK, Sood AK, Anderson B, Sorosky J, Lubaroff DM. Psychosocial factors and interleukin-6 among women with advanced ovarian cancer. Cancer 2005; 104: 305-313, doi: 10.1002/cncr.21147.

23. LeMay LG, Vander AJ, Kluger MJ. The effects of psychological stress on plasma interleukin- 6 activity in rats.
Physiol Behav 1990; 47: 957-961, doi: 10.1016/00319384(90)90024-X.

24. Ray A, Tatter SB, May LT, Sehgal PB. Activation of the human " $\beta_{2}$-interferon/hepatocyte-stimulating factor/interleukin 6" promoter by cytokines, viruses, and second messenger agonists. Proc Natl Acad Sci U S A 1988; 85: 67016705, doi: 10.1073/pnas.85.18.6701.

25. Xiao W, Hodge DR, Wang L, Yang X, Zhang X, Farrar WL. Co-operative functions between nuclear factors $\mathrm{NF}_{\kappa} \mathrm{B}$ and CCAT/enhancer-binding protein- $\beta(\mathrm{C} / \mathrm{EBP}-\beta)$ regulate the IL-6 promoter in autocrine human prostate cancer cells. Prostate 2004; 61: 354-370, doi: 10.1002/pros.20113.

26. Rohrbach S, Engelhardt S, Lohse MJ, Werdan K, Holtz J, Muller-Werdan U. Activation of AP-1 contributes to the $\beta$ adrenoceptor-mediated myocardial induction of interleukin-6. Mol Med 2007; 13: 605-614, doi: 10.2119/2007-00071. Rohrbach.

27. Ray A, Sassone-Corsi P, Sehgal PB. A multiple cytokineand second messenger-responsive element in the enhancer of the human interleukin-6 gene: similarities with c-fos gene regulation. Mol Cell Biol 1989; 9: 5537-5547.

28. Libermann TA, Baltimore D. Activation of interleukin- 6 gene

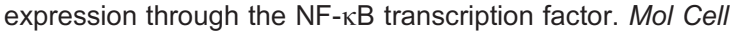
Biol 1990; 10: 2327-2334.

29. Sands WA, Palmer TM. Regulating gene transcription in response to cyclic AMP elevation. Cell Signal 2008; 20: 460466, doi: 10.1016/j.cellsig.2007.10.005.

30. Shaywitz AJ, Greenberg ME. CREB: a stimulus-induced transcription factor activated by a diverse array of extracellular signals. Annu Rev Biochem 1999; 68: 821-861, doi: 10.1146/annurev.biochem.68.1.821.

31. de Groot RP, Sassone-Corsi P. Activation of Jun/AP-1 by protein kinase A. Oncogene 1992; 7: 2281-2286.

32. Metz R, Ziff E. cAMP stimulates the C/EBP-related transcription factor rNFIL-6 to trans-locate to the nucleus and induce c-fos transcription. Genes Dev 1991; 5: 17541766, doi: 10.1101/gad.5.10.1754.

33. Shirakawa F, Mizel SB. In vitro activation and nuclear translocation of NF- $\kappa$ B catalyzed by cyclic AMP-dependent protein kinase and protein kinase C. Mol Cell Biol 1989; 9: 2424-2430.

34. Kondo A, Mogi M, Koshihara Y, Togari A. Signal transduction system for interleukin-6 and interleukin-11 synthesis stimulated by epinephrine in human osteoblasts and human osteogenic sarcoma cells. Biochem Pharmacol 2001; 61: 319-326, doi: 10.1016/S0006-2952(00)00544-X.

35. Wang $\mathrm{P}$, Zhu F, Konstantopoulos K. Prostaglandin E2 induces interleukin-6 expression in human chondrocytes via cAMP/protein kinase A- and phosphatidylinositol 3-kinasedependent NF-кB activation. Am J Physiol Cell Physiol 2010; 298: C1445-C1456, doi: 10.1152/ajpcell.00508.2009.

36. Ajuwon KM, Spurlock ME. Palmitate activates the NF- $\mathrm{BB}$ transcription factor and induces IL- 6 and TNF- $\alpha$ expression in 3T3-L1 adipocytes. J Nutr 2005; 135: 1841-1846. 